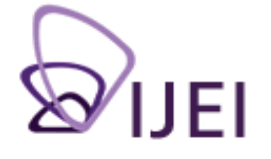

International Journal for Educational Integrity

\title{
Developing a platform for a culture of honest inquiry and the academic construction of knowledge in first-year students
}

\author{
Robert Craig \\ Petroleum Institute, Abu Dhabi, UAE \\ rcraig@pi.ac.ae \\ David Dalton \\ Petroleum Institute, Abu Dhabi, UAE \\ ddalton@pi.ac.ae
}

Keywords: academic integrity, plagiarism, engagement, curriculum

This paper was assessed by the Editors of the Conference Proceedings of the Plagiarism Across Europe and Beyond Conference (Brno, Czech Republic, 12-13 June 2013) as a 'best conference paper'. It was then forwarded to the IJEI for consideration. The paper has now undergone additional double-blind peer review and as a result of subsequent revisions is substantially different from the original version presented at the Czech conference.

\begin{abstract}
Academic misconduct is a concern in tertiary institutes globally with some perceiving it as endemic. Amongst the issues raised by this practice are serious ethical considerations and impacts on learning. If students are not doing their own work, what is actually being learned? The reasons why students plagiarise are therefore a legitimate area of study and may not be as straightforward as they first appear. This research was conducted at the Petroleum Institute $(\mathrm{PI})$, an engineering university and research institute in Abu Dhabi, United Arab Emirates.
\end{abstract}

The main objective of the research was to gather data which would highlight the perceptions first-year students have concerning the proportion and frequency of cheating among their peers. There was also interest in discovering what students considered to be the main reasons for such behaviour. Findings show that at the start of the undergraduate programme, three quarters to four fifths of the students viewed copying as serious or very serious. However, after only one semester this percentage had dropped considerably for some areas. Frequency of cheating also varied from the first to the second semester. The data established that there is a clear problem and indicates a need for change. In the context of the Communications Department, to which the researchers belong, courses were already in place within which issues of plagiarism and copying were minimal.

This paper presents the full findings of the investigation and describes an enquirybased approach adopted by the PI Communications Department in 2006 to lay the foundations for developing honest inquiry and the academic construction of knowledge. The approach aims to facilitate student engagement, ownership and buyin and has had a mitigating effect on copying and plagiarism. Recommendations are suggested for general changes across the curriculum, based on the experiences of the above mentioned programme.

The International Journal for Educational Integrity is available online at:

http://www.ojs.unisa.edu.au/journals/index.php/IJEI/

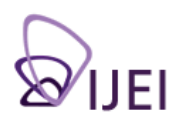




\section{Introduction}

This study was carried out at the Petroleum Institute in Abu Dhabi, United Arab Emirates in response to expressions of concern about copying and plagiarism, similar to those encountered in many tertiary institutes worldwide. That inappropriate copying and plagiarism are a major problem in many spheres would not be contested. Headline cases have included the suspension of Fareed Zakaria, the case of Romanian Prime Minister Victor Ponta, British journalist John Hari and locally, in our context, Dr Hafnaoui Ba'li who lost the prestigious Sheikh Zayed book award as a result of plagiarism. In higher education specifically it is considered by many to be "endemic in universities worldwide" (Sheard, Dick, Markham, Macdonald, \& Walsh, 2002, p. 183) and not only amongst students, with the University World News for example, claiming that research in Egyptian universities is "plagued by plagiarism" (Khaled, 2008, p. 1). This statement could probably be reasonably generalised to other parts of the world.

Our concern as educators and researchers is to focus on the behaviours of undergraduate students in respect to these practices and explore perceptions of copying and plagiarism amongst our student body in order to discover how seriously they viewed these issues. Recent research into plagiarism and copying in universities supports anecdotal perceptions that it is very widespread and varied in nature. A survey amongst 150 undergraduates conducted at the University of Pretoria in 2005 found that $80 \%$ of the respondents admitted to "frequently" plagiarising assignments (Russouw, 2005). According to one British newspaper ("More students," 2012), data derived from the university admissions system (UCAS) in the UK in 2011 revealed 8,500 students even copied personal statements written in their university applications! A survey conducted at Monash University (Australia) in 2001 found that $85 \%$ of respondents admitted to cheating with $33 \%$ stating that they copied from friends' assignments while doing some of the work themselves, $10.4 \%$ copied assignments from another students' computer without their knowledge and $22.4 \%$ copied from the internet (Sheard et al., 2002).

Donald McCabe is one of the leading researchers in this area, certainly in the US and Canada, and has conducted research with samples of up to 71,000 undergraduate students over a decade (McCabe, 2005). He has found that 'cheating' of various kinds is widespread and habitual. He has looked at a range of different academic environments where copying and plagiarism occur, including examinations, written assignments, research work and lab work. He found that, $42 \%$ of respondents worked with others on an assignment when asked for individual work, 38\% paraphrased or copied from a written source without footnoting and $36 \%$ did likewise when using the internet. Other elements were handing in assignments copied from other students and falsifying bibliographies. Exams provided another fertile area for suspect behaviour with $11 \%$ copying from another student during an exam, $8 \%$ using unauthorised notes and $5 \%$ using unauthorised digital or electronic devices. Recently the prestigious Harvard University ("Ivy league cheaters", 2012) recently launched an investigation after 'possible' cheating was discovered in roughly half the papers of a class of 279 students in the spring semester of 2011. The picture painted from the above cited research and supported by other studies as well as the day-to day discussions that take place between educators everywhere, clearly shows patterns of behaviour that are universal and apparently habitual.

Given that plagiarism and cheating are so common and give rise to a wide range of concerns, it is important to identify and discuss some of the issues and dilemmas it raises. These include ethical, philosophical, cultural, social, and pedagogical questions. Academic integrity, which most institutes of higher education would at least claim to have as one of their 'core values', requires honesty and fair play in the production of original documentation and in general academic practice. Copying the work of others whether in an examination or from the internet or other sources, 
breaches ethical guidelines and considerations and is reasonably considered by many to be a form of theft. Turning in plagiarised or copied work is also arguably unfair to those who produce their own work given that the 'copier' may receive a higher grade for work they did not do. This in turn undermines the integrity of the grading process and assessment system given that assessment in large part evaluates what an individual has (supposedly) learned.

Another issue is the effect on learning itself, which of course is the main reason most students attend university and the reason teachers teach. Plagiarism and copying of any kind, and particularly when it becomes habitual, means that valuable skills which form the core of the pedagogical process may well not be learned. For example, the research process involves a host of skills essential to that process but also skills for life. Evaluating sources, reading and note taking, annotating texts, paraphrasing and summarising are all skills which might be used later in a professional (work) environment. The process also involves key critical thinking skills especially in a discussion and recommendations section of a research report. If students are plagiarising and these skills are not effectively learned there is also an obvious effect on the quality of their preparation for later endeavours, including postgraduate study and work.

Apart from possible 'knowledge gaps', ethical issues are also raised, in that if students are little concerned about academic integrity, what might this suggest about predisposition to unethical behaviour in a professional environment? A study conducted by the Josephson Institute (2009) looked at the relationship between attitudes and behaviour in high school and later conduct in adult life. It found that those who cheated on exams in high school twice or more are considerably more likely to be dishonest in later life, compared to those who do not.

More immediate consequences for the student who is caught usually involve a range of penalties increasing in seriousness which can ultimately result in expulsion from their university. This is as well as the stigma of being publicly branded a 'cheat' which would likely appear on the student's personal record and could obviously impact their future life.

For those involved in a dynamic of copying and plagiarism, there are obviously reasons that generate such behaviours and personal perceptions related to these practices. It is likely that some forms of cheating will be viewed more seriously than others and indeed that some of the behaviours described may not be seen as cheating at all.

These were some of the issues focused on in our investigation at the Petroleum Institute $(\mathrm{PI})$ in Abu Dhabi, the capital of the UAE. At present, baccalaureate and postgraduate degrees are offered in chemical engineering, electrical engineering, mechanical engineering, petroleum engineering, and petroleum geosciences engineering and materials science and engineering. Set up in 2001, it is in the unique and fortunate position of being supported, financed and governed by a national oil company and its international partners. Approximately $70 \%$ of the undergraduates are Emirati and $30 \%$ expatriate. While the degree programmes are open to both male and female students, the two are, for the most part, segregated in order to comply with cultural sensitivities. The medium of instruction is English (as it is throughout higher education in the UAE) and for most of the student population it is an additional language. While some may be quite fluent, many have a relatively low level of language proficiency on entry to the degree programme. The investigation described below was carried out in response to expressions of concern about copying and plagiarism, similar to those encountered in many tertiary institutes worldwide. 


\section{Methodology}

The main objective of the research was to gather data which would highlight the perceptions first-year students at the PI have concerning the proportion and frequency of cheating among their peers. There was also interest in discovering what students considered to be the main reasons for such behaviour. A survey comprising five sections was developed to gather quantitative data which would answer the following four questions:

- Is academic dishonesty an issue at our institution?

- How serious do students consider it?

- How frequently do students believe it occurs?

- What are the reasons for such behaviour?

A $70 \%$ (approximately, $n=127$ ) response rate from a total of 185 first-year students was recorded, comprising 21 first-semester male students, 48 second-semester female students, and 58 second-semester males. As such we were able to consider gender differences as well as any changes in students' perceptions of behaviour that may have occurred between entering the degree programme and after the beginning of the second semester. Unfortunately, the response rate from first-semester female students was too low for us to be able to generalise across that population, and as such was discounted from the study.

The survey was organised into five sections. The first section sought to discover if students were aware of institutional policy, if they had read it, and if they understood it. Section two focused on student perceptions of the seriousness of eight common academic offences, and asked for ratings on a scale of 1 to 4 . This was followed by questions asking how frequently students had engaged in such behaviour, and a section on how common they believed this behaviour was among their peers. The purpose of the final section was to find the most likely causes of academic cheating. Participants were asked to rank 12 possible reasons which focused on time constraints, risk, skills and interest on a scale from 'most likely' to 'least likely'. (See Appendix A for full survey.)

\section{Main findings}

1. The first section of the survey was concerned with finding out if students were aware of the institute's academic integrity policy and honour pledge. The vast majority $(90 \%, n=106)$ of both second-semester male and female students stated they were, whereas just under a third of first-semester students $(n=21)$ claimed that they were not. Only half of these students had actually read the document. Four times as many male as female students surveyed said they did not actually understand it.

2. In response to the focus of the second section on student perceptions of the seriousness of academic cheating it can be surmised that approximately three quarters to four fifths of students $(n=127)$ who had recently begun their undergraduate programme believe that the items for consideration - copying homework, in a test, a colleague's answer, providing answers or doing homework for a friend or colleague, as well as plagiarising work and passing it off as their own and paying someone to do their work - are serious or quite serious academic offences. It was, however, surprising to discover that after one semester, this percentage had dropped considerably in some areas. For example, half the male and female students did not consider copying homework, doing the homework of a friend or having the friend do it for them to be serious. Any form of cheating in exams, quizzes or tests was still perceived to be a serious academic offence. 
3. The data also showed a change in the frequency of cheating from the first semester to the second. Almost all first-semester students claimed that they rarely or never copied homework from a colleague or from notes in a test, nor did they provide answers for their friends or pay someone to do their work. Just over a month into their second semester, around half of both male and female students stated that they frequently or sometimes copied homework assignments, and over a third of males allowed friends to copy homework and quizzes.

4. There is a strong belief, among second-semester male and female students in particular, that cheating in various forms is quite rampant, especially on homework assignments.

5. The final section of the survey asked students to identify what they considered to be the most likely reasons for poor academic integrity. The choices included poor time management, a low chance of being caught or reported, minimal penalties, worth the risk to get a better grade, normal behaviour, having actually been taught to copy in high school, lack of understanding of how to complete the assignment, too much effort required, the author's words are best, poor command of English, and a general lack of interest. For first semester students the most likely reasons were a lack of proper understanding of how to complete the assignment and it being worth the risk to get a better grade. This was followed by a general lack of interest, a lack of time, low penalties and the belief that the author's words were in fact too good to change. A low chance of being caught, too much effort required to paraphrase or their English not being good enough, did not rate as highly as probable reasons for cheating.

6. A semester of undergraduate study showed some changes in most probable reasons for such behaviour. Poor time management was clearly the most likely reason for students to cheat. Students were aware of the penalties but considered it worth the risk to achieve a higher grade. This was followed by a poor understanding of the task requirements.

7. While gender differences were generally not extreme, varying no more than 5 to $10 \%$ on most responses, data do suggest that females take cheating more seriously. For example, twice as many females as males stated that they had actually read the institute policy on academic honesty, and $90 \%$ of them believed that they fully understood it as opposed to about two thirds of the male students. Ten per cent more females than males consider cheating on exams, quizzes or tests, and helping friends in them, to be serious or quite serious, and two thirds of the female respondents and only half of the males believe that cheating on homework is serious.

\section{Discussion}

The main findings described above are consistent with other studies over the last 15 years (Akande, 1998; Carroll, Marsden, \& Neill, 2005; Freire \& Miranda, 2011; Spear \& Miller, 2012), with poor time management and low understanding of the task ranking high. One might assume that students studying in a second or additional language often struggle with tasks and this may cause some temptation to cheat but our results show that "lack of understanding of how to complete the assignment, too much effort required, the author's words are best, and a poor command of English" were not rated highly by respondents as causes for cheating. This may well be due to the nature of the curriculum in their chosen majors in engineering with a heavy focus on traditional math, chemistry and physics. However, language may be an additional factor here as anecdotal evidence indicates students misinterpret their teachers' instructions (one of the researchers is currently gathering qualitative data on this area) with an additional cultural element of students often not asking for clarification 
as they do not want to lose 'face'.

It is not surprising that students do not read the policy - length and sophistication level of the document, and the fact that few begin their undergraduate education having had any exposure to academic reading (especially in English) is hardly conducive to satisfactory compliance. Knowledge of policy does not, however, seem to be a factor in modifying behaviour with respect to cheating and plagiarism, perhaps in the same way that knowledge of traffic policy often has no impact on driver behaviour. Sheard et al. (2002) also indicated high levels of student awareness of policy (84\%) but little effect of this on levels and patterns of cheating. A further issue in our environment was the high number of students who did not understand the policy anyway. A need for more accessible language given that our students are native Arabic speakers may be required here as the style and lexis of 'policy language' can sometimes be rather mystifying, even to native speakers of the language the document is expressed in.

A low chance of being caught ranked fourth in the above study, but was not ranked highly for our sample. In the context of written assignments, particularly in required first-year communication courses at the PI, plagiarism detection software is used widely in some courses but not at all in others. This may explain the student perception that chances of being caught are low. Of course, it may also be that faculty might not be vigilant in this area. The findings do suggest that students understand the moral aspects of cheating but are selective in proportioning seriousness. Frequency changes in cheating between semesters can in part be explained by students prioritising which elements of which course to focus on in order to achieve a desired grade. This is not a perspective students arrive at in the first semester, but seems to be learned behaviour. By the second semester they have learned to develop strategies (possibly influenced by peers) to achieve a 'percentage' outcome. Testing appears to be taken far more seriously than learning and students develop strategies to deal with pressure and what they see as low priority. Unfortunately, homework and engaging in the learning process does not appear to merit the same worth as cramming for quizzes, tests and exams and this is likely to be the result of the culture of high schools in the region. It also perhaps due to the fact that many students at the beginning of the transition from high school to university do not understand that one of the main purposes of higher education is to foster intellectual growth through disciplinary inquiry; they tend to understand their new environment in terms of their somewhat limited high school experience of passing courses through the memorisation of knowledge, tested through quizzes and exams. This surface level approach to learning is both intellectually and physically less demanding, and if it is tolerated will likely provide far more opportunity for cheating than a curriculum which encourages deep learning (Akande, 1998). Recent moves towards a more active, experiential and inquirybased paradigm may well foster deeper learning, responsibility for learning and greater motivation, as opposed to the more traditional approaches which tend to encourage and reward dependency on surface learning strategies.

One thing that did surprise us a little was that students, who describe themselves as religious, living in a society which openly states its strong religious heritage, did not seem to have any perceptions of cheating as unethical. This is rather different from studies carried out with students in more (nominally) secular societies, such as the US. Rettinger's (2005) study indicates that:

among these religious students, more religiosity correlates with reduced reports of cheating in all courses. This result appears to be due to the unique effect of religion on self-reported cheating rates and, depending on course content, on a reduction of grade orientation in religious students. (p. 107)

We might have reasonably expected to find something similar here, but it was not apparent in our results. Other factors, such as Hofstede's (2001) uncertainty 
avoidance might also lead us to assume that cheating in general might be less likely to occur, especially given (under the social norms trait) a supposed tendency towards conservatism and a belief in law and order. Ergo, if your institute has a stated policy (law) against plagiarism and cheating you should follow it. This does not seem to be the case here, even though most local universities have academic integrity/honesty policies. For example, a local study ("Student cheating," 2012) indicated that $78 \%$ of respondents admitted to some form of cheating.

In general terms, the relationship between globalism and secularism is well explored (Alvey, 2003; Beyer, 1994) and while it is not the purpose of this paper to enter the debate, secularisation may well play a part in why our students behave in the same way as students anywhere. Further study would reveal the significance of this affective factor. Indeed, Hatherley-Greene (2012a) states that in the UAE, we might be "witnessing ... a neo-indigenous effect produced by globalization and the UAE's own 'cultural tsunami".

Others suggest that those who come from collectivist societies, societies which are considered to manifest high uncertainty avoidance, and with a synchronic/ short-term perception of time are perhaps more likely to adopt surface level approaches to learning, focusing on correct answers rather than process and analysis - a more individual approach favoured by the West (Hofstede, 2001). However, Hatherley-Greene's (2012b) study found that undergraduate students in the UAE do not consistently conform to the stereotype of the typical Arab cultural pattern. Further, they demonstrate quite a high level of cheating in areas they do not rate seriously, such as copying homework.

While ethical considerations and approaches to the 'hearts and minds' aspect of this problem should certainly be sustained, there are clearly issues with the usefulness of a uniquely ethics-based approach. Similarly, a lot of attention is given to detection and punishment. It may well be that both of these somewhat miss the point and that answers lie more in the sphere of curriculum, teacher/ student relationships, classroom organisation/management and the very nature of the courses and learning experiences we offer our students.

\section{Approaches to creating a culture of academic integrity}

How, then, do we change perceptions of learning and how do we move towards a more critical, deep learning approach when rote learning and the belief that there is one correct answer is a very common notion amongst our students?

All freshman students at the $\mathrm{PI}$ are required to complete a two-level communications programme based around a team primary-research project. Much of the thinking behind the programme and its design has been informed by two sets of learning principles - McCabe and Pavela's (2004) ten principles of academic integrity, and Chickering and Gamson's (1987) principles of good educational practice. As shown in Figure 1, academic integrity is the duty and concern of all members of the community. 


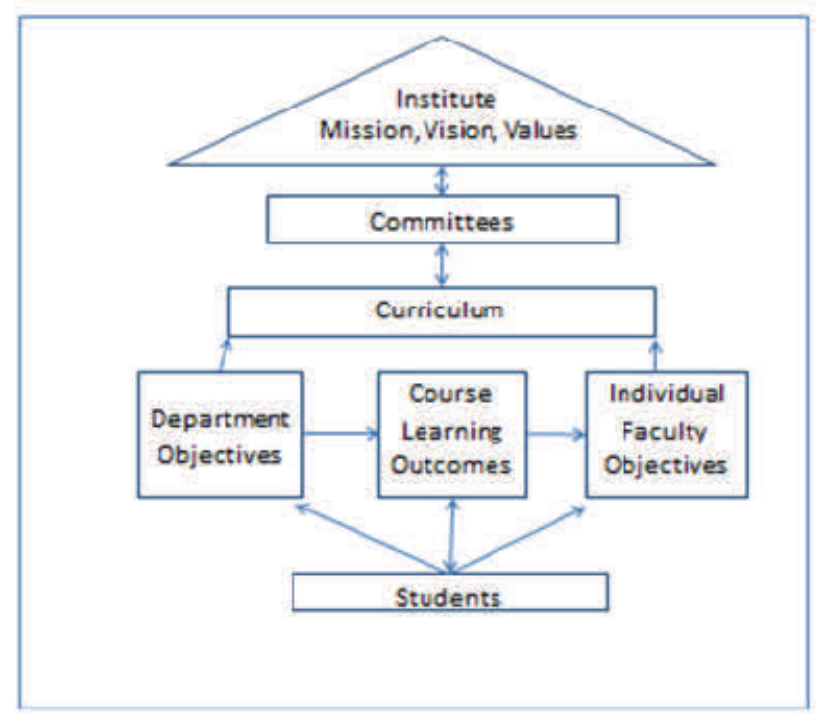

Figure 1. Responsibility for academic intergrity

One part of the PI's mission statement (n.d.) is to foster an "intellectual environment that leads to the development of our graduates as whole persons and as the future leaders in their respective fields of expertise". One aspect which reflects the whole person development of the graduating student is that they "should have the professional integrity and maturity to serve humanity and its highest values, and should always make ethical decisions as they relate to society, corporate operations, technology, and the environment". An academic honesty committee exists with the duty of considering incidences of cheating, recommending suitable sanctions, and, more recently, to make recommendations based on data for improvements to policy. A code of honour also exists, and students are required to sign a pledge attesting that each submission is their own work, and serves as a reminder of the institute's commitment to maintaining a culture of academic integrity.

Policy and sanctions alone, however, appear to do little to change student attitudes to copying and plagiarising. When the focus of much current practice is still very much on the ability to recall content, and provide answers rather than describe processes, there is abundant opportunity for students to resort to copying. A move towards a more active, experiential and inquiry-based paradigm is a more appropriate approach if learners are to become more responsible for their own learning, explaining understanding, and developing critical thinking. Consequent reduction in plagiarism might also be observed in such an environment (McGregor \& Williams, 2011, p. 12).

The first-year communication courses have been developed to compensate for the poor preparation many of our students have for the requirements of 21 st century undergraduate study. While the main objectives are to improve communication skills, enabling objectives include developing appropriate study skills, and applying critical thinking to reading and writing. These courses are well established.

These courses introduce students to real world research and ask participants to take on the role of apprentice researchers. Rather than being taught discreetly, language skills are developed in the context of a primary research project, and are "embedded in the nature of the activity rather than being taught in isolation or bolted on" (Craig, 2011). The research projects are team-based and once teams have identified and brainstormed (with appropriate instructor guidance) suitable topics for investigation (recent topics have, for example, included issues of high school to university transition), they are given instruction in library search strategies and are asked to provide a short written overview of the selected source, complete with a live link for 
the instructor. Following class activities in summarising, paraphrasing, the use of quotation and, equally importantly, the need to acknowledge sources of information, the next task is to write a summary. Substantial feedback is provided before teams begin working on synthesising their knowledge in a literature review which focuses on avoiding the production of "nothing more than a collection of summaries of papers or an elaborated bibliography" (Levy \& Ellis, 2006, p. 182). The process requires each team member to explain the content and relevance of their chosen article while team members take notes and ask for clarification. Themes are identified and each team member contributes information from their article, including main ideas, author beliefs, and findings from the study. Once this phase of secondary research is completed, teams are asked to localise the global issue. A formal proposal is required in which students outline the aims and objectives of their intended primary research, as well as identifying and producing a suitable data gathering instrument. As the research develops, students are required, individually and in teams, to describe, explain and justify each stage, culminating in collaborative written reports, and oral presentations. Documentation (proposal, methodology, findings, discussion and conclusion and recommendations) is generated by the primary research process, with each new text building on and incorporating edited elements of previous documents and developing schema and knowledge from that process. Given that the focus is on developing students' understanding, the need to turn to an external model to copy from is radically reduced and student ownership consequently increases.

Our students, however, are required to select articles based on how the concepts, ideas and practices contained in them can inform their research. The review is therefore not seen as a document in isolation, but rather integrated into the report as part of a raison d'être for decisions made in the research, such as informing methodology and, as such, demonstrates the quality of students' critical thinking. Themes used to organise and construct surveys, for example, are typically derived from the review, as are sub questions the research might focus on. The approach to the review (purpose) and the application of knowledge derived from it again reduces the need to plagiarise. It is therefore the nature of the tasks themselves which leads students to produce their own work. For instance, the recommendations section of the research report is approached first with a set of negotiated criteria as to what informs effective recommendations. These include identifying relevant stakeholders and beneficiaries, responsible parties who will apply the recommendations, appropriateness and applicability and so on, all of which is conditioned by the focus of the primary research of each team. It is simply not necessary (or really possible) to cut and paste a set of recommendations from some other context. Further, by this stage of the learning process, most students have a high level of buy-in and ownership and are more concerned with originality.

This approach has been successful, not only in demonstrating critical thinking and understanding of content, but also in significantly reducing plagiarism, as evidenced by similarity results from Turnitin; while we can expect up to $20 \%$ ( $n=200$, in Fall, and 120 students in the Spring semester) of the early source summaries to be largely plagiarised, there are very few occurrences in the following literature review. This is largely due to instructor feedback (and a demonstration of Turnitin!) and the fact that each stage is carefully scaffolded which removes the need for copying, as task fulfilment cannot be achieved through reliance on 'copy and paste' or lack of acknowledgement. Use of in-text citations is expressly required in the descriptive grading rubric we use for scoring written work. All such rubrics are used as teaching/ learning tools. Further, there is no content as such to be memorised or copied, and any attempts to fool the reader are easily detected and challenged. Each member of the team is responsible for making sure there is no plagiarism, and in the process learns to describe each stage of their research, supporting their observations with primary data and reference to the literature. Students develop ownership, buy into the approach which simulates real world, adult, professional activity, learn that task fulfilment is rewarded, and that not only is there no 'need' to cheat, there is no opportunity. 


\section{Conclusion}

The skills that are developed in these first-year communication courses can only be maintained if similar approaches are used across curriculum in all the institute's programmes. Expectations which are communicated to students through clear, achievable tasks and descriptions, transparent assessment and an inquiry-based approach to learning would be a huge step in developing a deeper conceptual understanding required for higher order thinking. The approach in the Communications Department courses has already influenced curriculum, assessment and pedagogy in the freshman and sophomore Strategies for Team-based Engineering Problem Solving (STEPS) programme which teachers from the Communications Department team-teach on. This type of cross-departmental collaboration achieves a number of purposeful ends, amongst which is to raise the issue of how to deal with plagiarism and the development of learning experiences designed to remove the need. Experiential and enquiry-based learning and the development of primary (original) research are cornerstones of the curricula in these courses.

The courses are developmental and connected and the teaching team speaks with one voice in regard to plagiarism and copying. Inconsistencies between teachers on such ethical issues can understandably confuse students as to expectations. Other departments are beginning to follow suit in applying inquiry-based approaches, and have adopted studio methods in the sciences. While no empirical data is available as yet, anecdotal evidence from instructors suggests that there is both less opportunity and need to cheat. Tasks are more concerned with documenting process and findings than with the memorisation of content and students report being far more engaged than in the traditional methods often found in engineering schools.

On an institutional level, the $\mathrm{PI}$ already has policy and guidelines as well as institutional responses to the issue. An Academic Honour Council is in place to deal with cases of plagiarism and copying, and to develop policy. All student-authored documentation includes an honour pledge signed by the students, and there are plans to locate this pledge into the contract all students are required to sign when they are offered a place at the PI. Additionally, there is also discussion about introducing the institute's academic honour policy in the first-year experience programme.

As educators, however, we are more interested in prevention, understanding why plagiarism and copying take place and developing approaches (of the kind described in the discussion) to render the behaviour unnecessary. As stated, these kinds of learning activities could usefully be extended to many other courses in the institute. A paradigm shift is required in order to achieve this. For example, courses which rely on a traditional lecture format for delivery (high information load) and testing for assessment (where the focus is on the grade) already have a teaching/assessment structure which lends itself to copying and plagiarism (Marsden et al., 2007). A number of courses in the PI fit such a description and this would need to change. An institute-wide re-evaluation needs to take place influenced by the model of 'good practice' described in the context of the communications courses (and latterly STEPS and Studio Physics) and clear expressions for the need for such change to continue should be led by departmental and senior management.

While a clear interest in the issue is becoming evident in the region, future research into academic honesty at higher education institutions in the region could well focus on faculty perceptions and practice (particularly levels of tolerance) and their approaches to dealing with incidents. Other research questions might determine differences between departmental responses, between new and long-term faculty, and also differences between local and expatriate faculty. 


\section{References}

Akande, A. (1998). Towards the multicultural validation of a western model of students approaches to learning. Education, 119(1), 37-47. Retrieved February10, 2012, from https://search.ebscohost.com/login.aspx? direct $=$ true \&db=a9h\&AN=1267317\&site=ehost-live\&scope=site

Alvey, J. E. (2003). Adam Smith's globalization (but anti secularization) theory. Discussion paper. Retrieved January 20, 2012, from http:// purl.umn.edu/23716.

Beyer, P. F. (1994). Religion and globalization: Vol. 27. London: Sage Publications Limited.

Carroll, M., Marsden, H., \& Neill, T. (2005). Who cheats at university? A self-report study of dishonest academic behaviours in a sample of Australian university students. Australian Journal of Psychology, 57(1), 1-10. Retrieved January 28, 2014, from https://web.a.ebscohost.com/ehost/pdfviewer/pdfviewer? vid $=3 \&$ sid $=06733$ edf $-91 \mathrm{a} 0-4505-\mathrm{a} 36 \mathrm{c}-70 \mathrm{c} 7 \mathrm{ce} 5 \mathrm{cb} 65 \mathrm{~b} \%$ 40sessionmgr4001\&hid $=4114$

Chickering, A. W., \& Gamson, Z. F. (1987). Seven principles for good practice in undergraduate education. AAHE Bulletin, 39, 3-6. Retrieved March 7, 2012, from: https://scholar.vt.edu/access/content/user/adevans/Public/DVDPortfolio/ Samples/samples/training/track d/Introduction/Best\%20Practices/Article\%20$\% 207 \% 20$ Principles $\% 20$ of $\% 20$ Good $\% 20$ Practice $\% 20$ in $\% 20$ Undergrad $\%$ 20Ed.pdf

Craig, R. (2011). Developing cognition and language proficiency through the acquisition and articulation of knowledge: Real world communication activities for engineering students in and across the disciplines. International Journal of Arts and Sciences, 4(10), 69-76.

Freire, C., \& Miranda, S. M. (2011). Academic dishonesty: Understanding how undergraduate students think and act. Paper presented at the ISATT Conference, July 2011, Braga, Portugal. Retrieved February 8, 2014, from http://repositorio.ipl.pt/bitstream/10400.21/1254/1/Academic\% 20dishonesty.pdf

Hatherley-Greene, P. (2012a, September 1). The reasons Emirati men struggle at university. Special to Gulf News. Retrieved September 1, 2012, from http:// gulfnews.com/news/gulf/uae/education/the-reasons-emirati-men-struggle-atuniversity-1.1066944

Hatherley-Greene, P. (2012b). Cultural border crossings in the UAE. Policy paper No 4. Shekikh Saud Bin Saqir al Qasimi Foundation for Policy Research. Abu Dhabi. Retrieved January 28, 2013, from http://www.alqasimifoundation.com/ Libraries/Publications/Pub8-paper Peter Hatherley Greene.sflb.ashx

Hofstede, G. H. (2001). Culture's consequences: Comparing values, behaviours, institutions and organizations across nations. (2nd ed.). Thousand Oaks, CA: Sage.

Ivy League cheaters: Harvard University investigating 125 undergrads "for plagiarizing test answers" (2012, August 30). Daily Mail. Retrieved January 15, 2012, from http://www.dailymail.co.uk/news/article-2195987/Half-Harvardclass-cheated-exam-University-investigating-125-undergrads-plagiarizinganswers.html.

Josephson Institute of Ethics. (2009). A study of values and behavior concerning integrity: The impact of age, cynicism and high school character. Retrieved April 8, 2012, from http://josephsoninstitute.org/surveys/

Khaled, A. (2008, July 20). EGYPT: Research plagued by plagiarism. University World News, 9(00246). Retrieved February 21, 2012, from http:// www.universityworldnews.com/article.php? $\underline{\text { story }=20080717165104870 \& q u e r y=\text { Research }}+$ plaqued+by+plagiarism 
Levy, Y., \& Ellis, J. T. (2006). A systems approach to conduct an effective literature review in support of information systems research. Informing Science, 9, 181202. Retrieved March 7, 2012, from http://www.scs.ryerson.ca/aferworn/ courses/CP8101/CLASSES/ConductingLiteratureReview.pdf.

McCabe, D. L. (2005). Cheating among college and university students: A North American perspective. International Journal for Educational Integrity, 1(1). Retrieved March 7, 2012, from http://www.ojs.unisa.edu.au/index.php/IJEI/ article/view/14/9

McCabe, D. L., \& Pavela, G. (2004). Ten (Updated) principles of academic integrity: How faculty can foster student honesty. Change, 36(3), 10-15. Retrieved March 12, 2012, from http://www.jstor.org/stable/40177967

McGregor, J., \& Williamson, K. (2011). Generating knowledge and avoiding plagiarism: Smart information use by high school students. School Library Research, 14, 1-22. Retrieved February 20, 2014, from http://www.ala.org/ aasl/sites/ala.org.aasl/files/content/aaslpubsandjournals/slr/vol14/ SLR GeneratingKnowledge V14.pdf

More students caught copying university applications. (2012, May 19). The Daily Telegraph. Retrieved June 4, 2012, from www.telegraph.co.uk/education

Petroleum Institute. (n.d.). Mission statement. Retrieved January 20, 2012, from http://www.pi.ac.ae/PI INS/eo/info/mission.php.

Rettinger, D. A. (2005). The relations among religion, motivation, and college cheating: A natural experiment. Ethics and Behavior, 15(2), 107-129. Retrieved December 12, 2012, from https://web.a.ebscohost.com/ehost/ pdfviewer/pdfviewer?sid=06733edf-91a0-4505-a36c-70c7ce5cb65b\% 40sessionmgr4001\&vid=5\&hid $=4114$

Russouw, R. (2005, February 26). Net closes on university cheats. Saturday Star. Retrieved March 2, 2012, from https://web.a.ebscohost.com/ehost/pdfviewer/ pdfviewer?sid=06733edf-91a0-4505-a36c-70c7ce5cb65b\% 40sessionmgr4001\&vid=5\&hid=4114

Sheard, J., Dick, M., Markham, S., Macdonald, I., \& Walsh, M. (2002). Cheating and plagiarism: Perceptions and practice of 1st year IT students. Proceedings of the 7th Annual Conference on Innovation and Technology in Computer Science Education (pp. 183-187). Retrieved March 8, 2012, from http:// dl.acm.org/citation.cfm?id=544414\&picked=prox

Spear, J. A., \& Miller, A. N. (2012). The effects of instructor fear appeals and moral aspects as cheating-related attitudes and behaviour of university students. Ethics and Behaviour, 22(3), 196-207. Retrieved January 28, 2014, from https://web.a.ebscohost.com/ehost/pdfviewer/pdfviewer?vid=7\&sid=c1 bf91697527-46f4-bf9b-c5639cb64fae\%40sessionmgr4005\&hid=4209

Student cheating is a serious problem in the UAE, academic says. (2012, August 18). Gulf News. Retrieved February 25, 2013, from http://gulfnews.com/news/ gulf/uae/education/student-cheating-is-a-serious-problem-in-the-uaeacademic-says-1.1061287. 
Appendix A

\begin{tabular}{|l|l|l|l|}
\hline \multicolumn{4}{|l|}{ Please tick $(\sqrt{ })$ appropriate box } \\
\hline Male & Female \\
\hline Freshman & Sophomore & Junior & Senior \\
\hline
\end{tabular}

\section{Survey}

This survey is being carried out to research student perceptions of the question of academic honesty in the PI. The results will be used to inform discussion on this issue. The survey will provide answers to the following four questions:

1. Is academic dishonesty an issue at the PI?

2. How serious do students consider it?

3. How frequently do students believe it occurs?

4. What are the reasons for such behavior?

Answers are confidential and will only be used by the researcher. Please answer all questions honestly. Thank you for your assistance.

\section{A. Institute Policy}

\begin{tabular}{|c|l|l|l|}
\hline 1 & Are you aware of an Academic Integrity Policy and Honor pledge at the PI? & Yes & No \\
\hline 2 & Have you read it? & Yes & No \\
\hline 3 & Do you understand it? & Yes & No \\
\hline
\end{tabular}

B. Perceptions of academic integrity/seriousness of 'offence' [4=very serious; $3=$ quite serious; $2=$ not very serious; 1 = not at all serious]

\begin{tabular}{|c|l|c|c|c|c|}
\hline 1 & Copying a homework assignment from a peer & 4 & 3 & 2 & 1 \\
\hline 2 & Copying from notes in an exam/test/quiz & 4 & 3 & 2 & 1 \\
\hline 3 & Copying a colleagues answer in an exam/test/quiz & 4 & 3 & 2 & 1 \\
\hline 4 & Providing answers to a friend/colleague in an exam/test/quiz & 4 & 3 & 2 & 1 \\
\hline 5 & Doing homework for a friend/colleague & 4 & 3 & 2 & 1 \\
\hline 6 & Having a friend a colleague do the work for you & 4 & 3 & 2 & 1 \\
\hline 7 & Plagiarizing work from others and passing it off as your own & 4 & 3 & 2 & 1 \\
\hline 8 & Paying someone to do the assignment & 4 & 3 & 2 & 1 \\
\hline
\end{tabular}

C. How often have you engaged in the following behavior? [4=frequently; 3=sometimes; 2=rarely; 1 = never]

\begin{tabular}{|c|c|c|c|c|c|}
\hline 1 & Copied homework assignment from a peer & 4 & 3 & 2 & 1 \\
\hline 2 & Copied from notes in an exam/test/quiz & 4 & 3 & 2 & 1 \\
\hline 3 & Copied a colleagues answer in an exam/test/quiz & 4 & 3 & 2 & 1 \\
\hline 4 & Provided answers to a friend/colleague in an exam/test/quiz & 4 & 3 & 2 & 1 \\
\hline 5 & Allowed a friend/colleague to copy your work & 4 & 3 & 2 & 1 \\
\hline 6 & Done homework for a friend/colleague & 4 & 3 & 2 & 1 \\
\hline 7 & Paid someone to do your work & 4 & 3 & 2 & 1 \\
\hline
\end{tabular}


D. How frequently do you believe the following occur?

[4=frequently; $3=$ sometimes; $2=$ rarely; 1 = never]

\begin{tabular}{|c|l|c|c|c|c|}
\hline 1 & Copying a homework assignment from a peer & 4 & 3 & 2 & 1 \\
\hline 2 & Copying from notes in an exam/test/quiz & 4 & 3 & 2 & 1 \\
\hline 3 & Copying a colleagues answer in an exam/test/quiz & 4 & 3 & 2 & 1 \\
\hline 4 & Providing answers to a friend/colleague in an exam/test/quiz & 4 & 3 & 2 & 1 \\
\hline 5 & Doing homework for a friend/colleague & 4 & 3 & 2 & 1 \\
\hline 6 & Having a friend a colleague do the work for you & 4 & 3 & 2 & 1 \\
\hline 7 & Plagiarizing work from others and passing it off as your own & 4 & 3 & 2 & 1 \\
\hline 8 & Paying someone to do the assignment & 4 & 3 & 2 & 1 \\
\hline
\end{tabular}

E. How likely do you think the following reasons might be given for academic dishonesty?

[4=Most likely; 3=Likely; 2= unlikely, 1= Most unlikely]

\begin{tabular}{|l|l|l|r|r|c|}
\hline 1 & Lack of time to complete assignment & 4 & 3 & 2 & 1 \\
\hline 2 & Low chance of being caught or reported & 4 & 3 & 2 & 1 \\
\hline 3 & Penalties are minimal & 4 & 3 & 2 & 1 \\
\hline 4 & Worth the risk to get a better grade & 4 & 3 & 2 & 1 \\
\hline 5 & Normal behavior (everyone does it/not considered serious) & 4 & 3 & 2 & 1 \\
\hline 6 & Taught to copy in school & 4 & 3 & 2 & 1 \\
\hline 7 & Lack of understanding of how to complete assignment & 4 & 3 & 2 & 1 \\
\hline 8 & Never been taught how to paraphrase and quote & 4 & 3 & 2 & 1 \\
\hline 9 & Too much effort required to paraphrase and quote & 4 & 3 & 2 & 1 \\
\hline 10 & Authors' words are best & 4 & 3 & 2 & 1 \\
\hline 11 & English not good enough & 4 & 3 & 2 & 1 \\
\hline 12 & Lack of interest & 4 & 3 & 2 & 1 \\
\hline
\end{tabular}

\section{About the authors}

Robert Craig was born and educated in Britain. He has been involved in education for almost 40 years and has worked in the UK, Oman, Angola, Brunei, UAE and Morocco. He presently teaches in the Communication Department, which he set up and headed until 2010, at the Petroleum Institute, in Abu Dhabi. His main research interests include the integration of content and language, effective communication, collaborative learning, outcomes based curriculum design, and assessment.

David F Dalton was born in Glasgow and attended universities in Birmingham, Manchester and Sheffield. He is a Senior Lecturer in Communications. He has worked in Spain, Mexico, Greece, the UK and the United Arab Emirates. He currently holds a position in the Faculty of Arts and Sciences in the Petroleum Institute in Abu Dhabi and was a member of the team which set up Sheikh Zayed University in Dubai - the first women's university in the UAE. 